\title{
Dispositivos para la alineación de funcionarios docentes durante la dictadura cívico-militar en Uruguay (1973-1985)*
}

\section{Revista Colombiana \begin{tabular}{l|l} 
Artículos históricos & $\begin{array}{l}\text { de Educación, N }{ }^{\circ} 65 . \\
\text { Segundo semestre de } 2013\end{array}$
\end{tabular} Bogotá, Colombia.}

\section{//Mechanisms for the alignment of education staff during the civil-military dictatorship in Uruguay (1973-1985) \\ //Dispositivos para a alienação de funcionários docentes durante a ditadura civico-militar no Uruguay (1973-1985)}

Andrea Cantarelli**

\section{Resumen}

La institución de formación docente y su diseño curricular constituyen áreas estratégicas para impulsar el proyecto político-pedagógico por parte de las Fuerzas Armadas durante la dictadura cívico-militar en Uruguay. En este trabajo el currículo es analizado como dispositivo de poder político-pedagógico desde la perspectiva foucoultiana. En la institución, el currículo fue puesto en práctica para disciplinar, para gobernar y clasificar $y / 0$ descalificar a quienes en este trabajo Ilamamos funcionarios docentes.

\section{Abstract}

The institutions of teacher training and curriculum design were strategic areas in which the armed forces could promote a particular political-pedagogical project during the civil-military dictatorship in Uruguay. In this article the curriculum is analysed from a Foucauldian perspective as a tool of political-pedagogical power. The curriculum was put into practice in order to discipline, to govern, and to qualify or disqualify those who in this article will be called education staff.

\section{Resumo}

A instituição de formação de professores e seu currículo constituíram áreas estratégicas para impulsionar o projeto político-pedagógico por parte das Forças Armadas durante a ditadura cívico-militar no Uruguay. Neste trabalho o currículo é analisado como dispositivo de poder político-pedagógico desde a perspectiva foucaultiana. Na instituição, o currículo foi posto em prática para disciplinar, para governar e classificar e/ou desqualificar os chamados funcionários docentes.

\section{Palabras Clave}

Currículo, institución educativa, dispositivo, sujeto, funcionarios.

\section{Keywords}

Curriculum, educational institution, device, subject, civil servants.

\section{Palavras chave}

Curriculo, instituição educativa, dispositivo, sujeito, funcionários docentes. 
El propósito de este trabajo es dar cuenta de lo acaecido en el campo educativo en la última dictadura cívico-militar (19731985) en Uruguay en lo que respecta a la modificación del currículo en formación docente.

La modificación implementada en 1977, Ordenanza N.o 29 del Conae ${ }^{1}$, de los planes de estudio de las carreras de Maestro de Educación Primaria, Profesor de Educación Media y Maestro Técnico fue el cambio curricular que introdujo lineamientos generales de las políticas educativas de la última dictadura cívico-militar en la formación de los docentes. Antes del periodo mencionado, las carreras de nivel terciario funcionaban con un currículo perteneciente a un núcleo básico relacionado con su especificidad.

Este trabajo busca describir algunos cambios que a nivel curricular se erigen como dispositivo en la institución. El dispositivo lo concebimos desde Foucault como la relación o red de saber/ poder en el que se inscriben la fábrica, la escuela, el cuartel, el convento y no cada uno de ellos en forma separada. Es decir, el dispositivo es la relación entre los distintos componentes institucionales, que incluye discursos, instalaciones arquitectónicas, decisiones reglamentarias, leyes, enunciados científicos, morales y filosóficos que circulan dentro de una relación. Foucault dice que el dispositivo es la red que se establece entre estos elementos, y tiene un espacio y tiempo definido históricamente, su emergencia responde a un acontecimiento que es lo que lo hace aparecer. El significado de diagnosticar la realidad en Foucault consiste en establecer lo que constituye nuestro presente, los acontecimientos que repetimos. Pero la actualidad no es solo el presente en el sentido de repetición, diagnosticar la actualidad consiste en marcar las diferencias, no se trata de comprender el presente a partir del pasado ni del futuro, sino en su diferencia, a partir de sí mismo.

El dispositivo curricular es puesto en contexto como un conjunto de principios sobre qué y cómo enseñar, creados por la necesidad de controlar y gobernar la educación. Supone una selección predeterminada de contenidos, de conocimientos que el docente debe enseñar, con previa indicación de métodos sobre cómo proceder, por ejemplo, la secuenciación y control del conocimiento. Lo curricular implica ciertas intenciones del gobierno sobre el sistema educativo; en este caso, es expresión del proyecto educativo de la dictadura. En el contexto dictatorial se introduce un currículo con clara intención de control sobre 
cómo deben transmitirse los contenidos, y no solo con la intención de controlar esos temas por enseñar. Pretendemos aportar a la interpretación de este fenómeno, evidenciando cómo se organiza la voluntad de gobierno sobre los sujetos $y$, particularmente, en las relaciones que estos debieran tener con los saberes que se busca transmitir.

Durante la dictadura, el dispositivo opera en el currículo (planes y programas) sobre la racionalidad entre los docentes y estudiantes. Aquí tuvo una función estratégica que se convierte en control-sujeción ${ }^{2}$; porque, una vez constituido, permanece en la medida en que tiene lugar un proceso de sobredeterminación funcional: cada efecto entra en resonancia o contradicción con los otros y exige un reajuste.

Qué sucedió con la educación, con los sujetos de la educación, en la institución educativa durante la dictadura como realidad única y diferente. Nos importa el análisis de las prácticas, retomando los conceptos usados por Foucault de episteme y dispositivo.

Se entiende la episteme como práctica discursiva, es decir:

[...] Conjunto de reglas anónimas, históricas, siempre determinadas en el tiempo y en el espacio, que han definido, para una época dada y para

2 Foucault lo asimila a la locura. Es posible que en el momento histórico que estamos analizando, se instale algo de locura o enfermedad mental entre los sujetos, dado que hay alienación. un área social, económica, geográfica o lingüística dada, las condiciones de ejercicio de la función enunciativa (Castro, 2004, p. 111).

Los dispositivos integran las prácticas discursivas como objetos de análisis, aparecen ante la necesidad de incluir las prácticas no discursivas (las relaciones de poder) entre las condiciones de posibilidad de la formación de los saberes. En cambio, la episteme es un dispositivo específicamente discursivo que tiene que ver con la disposición de los enunciados dentro de una teoría científica. El dispositivo que después conforma está determinado por las prácticas sociales y el poder que las atraviesa, a través de formaciones discursivas y no discursivas. Para el pensamiento clásico, lo discursivo sería el soporte de la institución, mientras que para Foucault, sería todo lo que el individuo aprende y que lo constriñe. El currículo de formación docente de la dictadura militar será objeto de descripción genealógica y, por ende, los individuos - funcionarios docentes - serán los encargados de ponerlo en acto.

Trabajaremos la idea de que la institución de formación docente individualizó a los sujetos, a través de tácticas y estrategias utilizadas desde el poder político mediante dispositivos como el currículo para que acontezca un individuo disciplinado.

Los dispositivos disciplinarios son isotópicos o tienden a serlo, lo cual 
quiere decir varias cosas, por ejemplo: tienen elementos subordinados y superordinados, es decir, los individuos poseen locus dentro de la institución e incluso dentro de una clase; por otro lado, quiere decir que entre los diferentes dispositivos no puede existir conflicto ni incompatibilidad, deben poder articularse entre sí. Esta característica de isotopía es coherente con el proyecto de las Fuerzas Armadas (FF. AA.) de unificar el sistema educativo en el ciclo básico. No podía sostenerse si había incompatibilidad de doctrina, todos debían mantener la coherencia en ese sentido para poder llevar a cabo la reestructuración del sistema educativo. Para ello, una de las estrategias fue eliminar todo elemento foráneo y corrosivo que pudiera contaminar la formación de futuros docentes.

En este momento histórico se instala, además, el dispositivo miedo como estrategia política; los individuos fueron utilizados con fines políticos para que los objetivos del régimen se cumplieran.

Lo curricular, expresado en planes de estudios y programas, es un discurso visto desde el contexto dictatorial prescriptivo. Para el caso de esta reforma curricular llevada adelante en dictadura, buscaremos rastrear elementos autoritarios en la forma en como estos discursos buscan tener efectos en la realidad educativa.

Esto necesariamente remite a la historia de la educación uruguaya, a la estructuración del campo, a la configuración de las instituciones, sus fines, su organización y, en general, al intento de gobierno de la educación mediante políticas específicamente educativas.

En este sentido, lo curricular es una dimensión más de las políticas educativas, es decir, pertenece al conjunto de prácticas que se instala en las instituciones a través de las cuales se crea un determinado orden, organizando la coexistencia humana. Por tanto, lo curricular configura una fuente importante en la medida que es acto de ciertas intenciones de gobierno en el campo, es expresión de un proyecto educativo que pretendemos sea interpretado. Es necesario explicitar que el énfasis está puesto especialmente en la formación moral de la persona.

Nuestra hipótesis es que a través de lo curricular se contribuía a restaurar el fortalecimiento de una nueva unidad de doctrina nacional. Lo curricular, expresado en planes de estudios y programas, se convierte en un discurso prescriptivo en el que podrán ser rastreados elementos autoritarios. Esto supone acercarse a los supuestos pedagógicos que guiaron este proyecto y cómo reciben una traducción política en un ordenamiento curricular. Los planes 
y programas de formación docente constituyen el proyecto en el que se muestra un reglamento autoritario visible en la institución educativa.

Es la institución el lugar estratégico donde llevar a cabo este proyecto político-educativo, por tanto, lo analizamos como un espacio de poder, desde la perspectiva foucaultiana. Es posible pensar que en las instituciones educativas hay rasgos singulares que las diferencian de las instituciones sociales. Nos referimos a que hay en la institución educativa un conjunto de órdenes que promueven la enajenación del individuo y lo empujan a una inserción cultural prefijada a su deseo, además de entregar un cúmulo de conocimientos también prefijados que se van acumulando y transforman al individuo en un sujeto alienado. Incluso en su uso más antiguo, la palabra institución alude a normas-valor de alta significación para la vida de un determinado grupo social, fuertemente definidas $y$ sancionadas - formalizadas, en el caso de leyes - con amplio alcance y penetración en la vida de los individuos (Fernández, 1994, p. 35).

En la institución escolar $y$, en general, en las instituciones donde se manifiesta una función formativa, la pedagogía institucional nació a su vez de una crítica referida tanto al uso hecho del sustrato material ${ }^{3}$

3 Lourau llama sustrato material cuando se refiere a los instrumentos de análisis (son un conjunto de conceptos articulados como sistema de referencia del análisis institucional), entre ellos, la distancia práctica. como a la organización del sistema de enseñanza.

Las técnicas educativas surgidas del movimiento Freinet ${ }^{4}$ eran ya una impugnación del espacio educativo, de las técnicas corporales, de la relación con los objetos presentes en el aula. Por la influencia de Rogers, la pedagogía no directiva insistió en el reordenamiento del grupo maestro-alumnos; este grupo dispuso los pupitres en círculo para facilitar el intercambio y, sobre todo, para simbolizar la muerte del curso magistral, no sin encontrar numerosas resistencias provenientes tanto de los alumnos y los maestros como del mobiliario escolar y del personal de maestranza.

La pedagogía institucional tomó por objeto el conjunto del espacio educativo para develar allí los símbolos de la burocracia escolar, símbolos a su vez del sistema social represivo: las modalidades de ingreso y egreso, la distribución de locales, la ausencia de ciertos canales de comunicación y la singularidad de los canales existentes, etc., todo lo cual ha servido y sirve de soporte al análisis del sistema institucional como

nombrado durante el curso, quien consideraba demasiado sistemático el método Cousinet en el sentido de que, para bien o para mal, es un sistema de estudio, si no a la manera vieja, sí la vieja materia en libros viejos. La actividad natural del niño, para Freinet, se desenvuelve en el grupo, es cooperativa; pero justo por eso no hay que coartarla ni desviarla hacia tareas extrínsecas, como tampoco entregarse a los mitos de la espontaneidad. El niño normal tiende a organizar su primitiva experience tâtonnée (de esta experiencia a tientas había hablado Claparède) en forma cada vez más rica tiende a convertirse naturalmente en sociales (Abbagnano y Visallberghi, 1987, p. 678). 
fundamento invisible e inconfesado de la educación. Este análisis permitió mostrar cuán poco adecuadas eran las instituciones educativas, y las instituciones en general, para su función oficial de formación. Más allá de la función educativa surgió, como en palimpsesto, la sociedad misma, es decir, la sociedad pretendidamente instituyente. La dialéctica de lo instituyente y de lo instituido se desarrolla así: "Hay lo social instituido, pero esto presupone siempre lo social instituyente" (Lourau, 2007, p. 89). Este mismo autor dice algo representativo para nuestro trabajo:

En épocas normales, lo social se manifiesta en la institución, pero esta manifestación es verdadera y a la vez falaz en cierto modo como indican los momentos en que lo social instituyente irrumpe y emprende su tarea sin intermediarios: los momentos de revolución. Pero esta tarea apunta inmediatamente a un resultado: darse de nuevo una institución para existir en ella de manera visible; y cuando esta institución queda planteada, lo social instituyente se aparta, toma distancia, se encuentra ya también en otro lado (p. 90).

La cita antes mencionada describe la dinámica de la burocracia institucional, quizá durante la dictadura cívico-militar se hizo más visible por todo lo acontecido (destituciones y restituciones arbitrarias, por ejemplo) 5 . Sería interesante estudiar cómo se desenvolvieron aquellos docentes y demás funcionarios que quedaron al servicio.

Es por ello que nos importa el análisis de la institución educativa, para comprender, como señala Malinowski (2007, p. 127), el momento cultural, dado que entendemos el proyecto político-pedagógico de las FF. AA. como un proyecto más amplio, justamente, de índole cultural.

\section{Primera parte: el dispositivo curricular para la formación de la persona}

Si bien el 16 de setiembre de 1971 el Poder Ejecutivo remite al legislativo un proyecto de ley sobre el control de la enseñanza, en 1977 anuncia:

5 En próximos trabajos, pensamos analizar cómo la figura docente logró resistir al régimen, configurando de esta manera una identidad. 
En la definición de políticas y estrategias del gobierno uruguayo $y$ análisis de la instrumentalización del plan de desarrollo: se declara que de acuerdo con las necesidades específicas de la educación y las necesidades de desarrollo social, cultural, científico y económico de la nación, se estructurará el régimen educativo a fin de adecuarlo a las exigencias del momento histórico dentro del tradicional estilo de vida oriental (Acto Institucional N. ${ }^{\circ}$ 7, citado en Apprato y Artagaveytia, 2004, p. 234).

Así es como se implanta, en los institutos de formación docente, el Plan 77, que unifica parte de las asignaturas de las carreras de formación de docentes para distintos niveles del sistema y reduce la carrera a tres años. Ambos elementos, y no solo la reducción en la extensión, resultan relevantes para la nueva economía aplicada en el diseño curricular analizado. La modificación tiene un carácter cualitativo que probablemente es el que mejor muestra ciertas novedades que se desea introducir en el sistema. Estas novedades van más allá de una disminución en la calidad de la enseñanza que se imparte: esta misma enseñanza implicará sesgos propios (anexo cuadro 2).
La introducción de un núcleo común ${ }^{6}$, que aparece para los maestros de enseñanza primaria concentrado en el primer curso, mientras que para los profesores está distribuido a lo largo de los tres años, es una de estas reorganizaciones que, de la manera en que son Ilevadas a cabo, dicen algo de las formas en que se pretendió ejercer el gobierno durante la dictadura.

Los documentos dan cuenta de cómo estas innovaciones están asociadas a la reestructura que se opera en todo el sistema educativo dependiente de la Conae ${ }^{7}$ :

[...] Cuyo objetivo fundamental es la formación del hombre uruguayo, de acuerdo a una concepción humanística y personalista que permita atender el encauzamiento científico necesario [...]. En consecuencia las tres ramas del Sistema Educativo Conae deben sustentar la misma unidad de doctrina, para lo que es imprescindible que todos

6 Habrá un núcleo común de asignaturas básicas de carácter técnico-pedagógico, integrando los tres factores interactuantes en el proceso educativo:

"[...] El educando en un enfoque evolutivo; los psicodinamismos del aprendizaje; el contexto social nacional que condiciona los otros factores" (Plan para la Formación Docente, 1977, Ordenanza 29).

7 Comisión Nacional de Educación, creada en la Ley 14.101 de 1973. Este organismo supone una importante modificación en los órganos de conducción del sistema de enseñanza pública que, junto a otras, introdujo dicha ley. 
los docentes estén imbuidos de los mismos ideales del sentir nacional y poseer un amplio espectro cultural y formativo que defina paradigmáticamente el perfil de los futuros ciudadanos (Conae, 1977, Plan para la Formación Docente).

Del propio texto de la resolución surge un elemento novedoso y que posibilita el estudio del Núcleo Común: la necesidad de la unidad en el sistema. Esta modificación, original de este plan, condensa una forma de entender lo educativo propia del régimen. Hay una búsqueda de economizar esfuerzos en tanto que todas las actividades educativas, sea cual fuere el nivel del sistema en que se encuentren o su naturaleza, deben remitir a cierto núcleo duro del proyecto. Hay algo común que requiere la formación de todos los profesionales del sistema para que este se vuelva efectivo en el cumplimiento de sus fines, y eso puede ser traducido curricularmente en un conjunto de conocimientos que todas las carreras docentes incluirán. Esto supone una unidad en el proyecto que se está llevando adelante, que en reiteradas ocasiones será presentado en contraposición a un pasado dominado por dinámicas perjudiciales y corrosivas.

Hay en esto una importante productividad en materia educativa, ya que se construyen dispositivos que buscan efectivizar el programa, lo que resultaría en una nueva forma de convivencia y ejercicio político que superaría el enfrentamiento, la fragmentación, la corrupción por agentes foráneos, antinacionales. Este es el punto en el que el proyecto general de la dictadura para toda la sociedad uruguaya se enlaza con el sistema educativo: las instituciones educativas tienen un papel central en este proyecto nacional. Debidamente desterradas las formas anteriores que permitieron que se infiltraran prácticas consideradas corruptoras y antinacionales —según los militares y civiles al frente del régimen-, los establecimientos educativos de todo el país tendrían la misión de formar a las nuevas generaciones apegadas a una serie de ideales. Las líneas directrices de esos cambios se irían articulando tanto en documentos curriculares, como en libros de textos, pero también en normativas, reorganizaciones de los tiempos y los espacios, entre otros. Pero, por otra parte, el propio papel de las fuerzas armadas y sus acciones en el país tienen una fuerte dimensión pedagógica y, particularmente, moral: acompaña a la introducción de manera autoritaria de aspectos políticos y económicos nuevos un fuerte componente cultural, de 
formación tanto de la persona como del cuerpo de la nación. Es aquí donde la totalidad del régimen lleva asociada una dimensión educativa.

De algún modo, la centralidad doctrinaria de la formación de la persona para el reencauzamiento de la sociedad uruguaya en sus mejores tradiciones, tal como en diversas oportunidades puede leerse, supondrá un reordenamiento en los conocimientos curricularizados para la formación de los docentes. Este aspecto doctrinario supone centrar la tarea educativa. Lo que se enseñe como contenido específico deberá operar en el conjunto de la formación de una manera tal que la primacía esté en la formación moral. Los contenidos que pueden ser entendidos como estrictamente intelectuales cobrarán un nuevo valor formando parte de lo que los documentos oficiales llaman formación integral. En el diseño curricular de las carreras docentes, esto está presente en la forma en como se articulan los cursos del núcleo común y las disciplinas específicas. Estas últimas corresponden a los contenidos disciplinares que el docente en formación enseñará luego en su actividad profesional; mientras que los cursos del núcleo común son los contenidos transmitidos a todos los futuros enseñantes, con especial énfasis en la formación moral de la persona, en los que están presentes los distintos aspectos de cómo enseñar y sobre todo el para qué enseñar. La relevancia de lo que se enseña está en función de cómo se articule con la dimensión doctrinal, y esta doctrina está contenida en el núcleo común.

Hay cursos dedicados a la formulación, generalmente expresa, de un conjunto de aspectos doctrinales de un nuevo proyecto educativo $y$, por otro lado, hay un conjunto de cursos que contienen una cierta diversidad de conocimientos de carácter instrumental con un fuerte énfasis en aspectos de tecnología educativa, que suponen una concepción propia de la tarea de enseñar y que han de estar al servicio de las primeras en aras de la eficacia y eficiencia del sistema. Encontramos dos ejes, uno de ellos contiene los aspectos doctrinales del proyecto, se incluye el curso de Teoría de la Educación y de Ciencias Sociales de Formación. El otro contiene los aspectos instrumentales y tecnológicos, y agrupa a Psicología de las Edades, Psicología del Aprendizaje, Evaluación, Didáctica General. Ambos constituyen las materias del Núcleo Común, donde se hace énfasis en "la formación moral de la persona".

$\mathrm{Si}$ se comparan las materias del Núcleo Común del Plan 77 con los planes inmediatamente anteriores (55 y 74 de magisterio y 65 de profesorado), más allá de la novedad que supone la existencia de estos contenidos únicos, que puede ser interpretada en las claves ofrecidas anteriormente, son visibles algunos cambios. Por ejemplo, no habrá curso de historia de la educación alguno, que sí estaba presente en todos los planes anteriores, se incorpora un curso de Didáctica General (ya presente en el 
plan del 74 de maestros), otro de Idioma Español como asignatura instrumental a la tarea de todos los docentes y se crea un curso sui géneris Ilamado Ciencias Sociales de Formación ${ }^{8}$, que presenta un conjunto interesante de peculiaridades, entre otras cosas porque no responde a un campo epistémico fácilmente reconocible (no se trata de sociología por ejemplo, que está presente en todos los planes anteriores). (anexo, cuadro 1).

\section{Segunda parte: la institución educativa}

La institución fue un ámbito privilegiado para la eliminación de la oposición y para la adhesión al consenso de discursos hegemónicos impuestos desde la coacción, con clara intención política del gobierno autoritario, cuyo poder ${ }^{9}$ estaba abocado a controlar el discurso político, lo cual repercute directamente en la conformación de subjetividades, dice Lechner:

El objetivo de los golpes no es tanto el derrocamiento de determinado gobierno como la fundación de un nuevo orden. Se busca imponer una normatividad y normalidad mediante procedimientos propios lógica de guerra: la aniquilación del adversario y la abolición de las diferencias (Lechner, 1995, p. 20).

Es necesario entonces pensar la institución y su articulación con lo curricular, porque es a través del currículo de los programas que se impone el proyecto político-pedagógico de forma aparentemente natura $/^{10}$. Incluso, es a través de la Ley 14.101 que se justifica mantener el orden y la seguridad social. Esta ley pretende abarcar todo el proceso educativo y, por tanto, determina no solo lo que debe acontecer en las instituciones de enseñanza, sino que llega al extremo de reglamentar, además, el comportamiento de los padres hasta el punto de quitarles la patria potestad de sus hijos si se ponía en riesgo la salud mental del menor.

¿Cómo es la institución de formación docente? ¿Cómo abordar este concepto?

8 Esta materia merece un estudio detallado, ya que parece ser un modelo de los escritos del coronel Soto. El programa consiste en una enumeración de contenidos que merece la pena leer para su posterior análisis.

9 Poder centralizado en el Conae.

10 Podemos sostener que no hubo conflicto — por lo menos visible - entre los directamente involucrados, es decir, los docentes, en el momento de llevarlo a la práctica. Esta afirmación no intenta ser extrema, alude a entrevistas realizadas por mí a docentes que trabajaron en las instituciones de formación docente durante la dictadura cívico-militar. Dichas entrevistas serán utilizadas para futuros trabajos. 
Revisemos algunas ideas de técnica determinada de poder, ligaFoucault:

[...] La noción reinstitución oculta una serie de insuficiencias, de peligros [...]. Ante todo, abordar los problemas de la psiquiatría a través de ella equivale a darse objetos ya plenamente constituidos: el colectivo y sus regularidades funcionales, el individuo que lo integra, etc., cuando en realidad convendría analizar sus procedimientos de constitución en el nivel de las disposiciones de poder y los procesos de individualización que estas entrañan (Foucault, 2005, p. 413).

Foucault intenta despegarse del abordaje de la institución totalitaria, que caracteriza a los establecimientos por la custodia de los individuos y el control de su modo de vida; es decir, tomar la institución para reubicarla simplemente en un abanico de otras instituciones omite mostrar que el asilo es una respuesta a una problemática histórica en evolución. Nosotros pensamos la institución de formación docente como problema, no planteado por la institución misma y su funcionamiento, sino en el sentido que Foucault le dio a su curso ${ }^{11}$ : saber cómo una

11 Curso dictado entre el 7 de noviembre de 1973 y el 6 de febrero de 1974, dedicado al poder psiquiátrico. da a estructuras sociales y políticas, autoriza "la racionalización de la gestión del individuo" (p. 414).

En este trabajo, el eje de análisis en la institución es el poder ${ }^{12}$, el poder disciplinario. Sobre él dice Foucault:
Por ello, no entiendo otra cosa que cierta forma ter- minal, capilar del poder, un último relevo, una modalidad mediante la cual el poder político y los poderes en general lo- gran, en última instancia, tocar los cuerpos, aferrar- se a ellos, tomar en cuen- ta gestos, los comporta- mientos, los hábitos, las palabras; la manera, en síntesis, como todos esos poderes, al concentrarse en el descenso hacia los propios cuerpos y tocar- los, trabajan, modifican y dirigen lo que Servan Ilamaba las fibras del ce- rebro ${ }^{13}$ (p. 59).

Intentaremos analizar el mecanismo que las FF. AA. Ilevaron adelante

\footnotetext{
12 En un próximo trabajo monográfico, nos detendremos en el eje de la subjetivación. El análisis se realizará a través de las entrevistas a docentes de formación docente durante la dictadura cívico-militar.

13 Esta es la primera hipótesis de trabajo de Foucault sobre el poder disciplinario. La segunda es que ese poder tiene en su especificidad una historia que eclosiona, es decir, se convierte en una forma social generalizada con el Panóptico de Bentham, que presenta con exactitud la fórmula política y técnica más general del poder disciplinador.
}

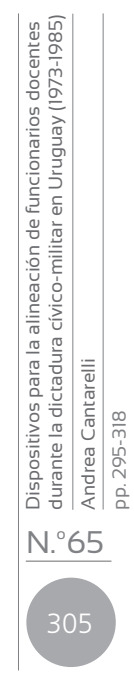


en los institutos de formación docente, basándonos en el concepto de poder disciplinario. Recordando nuestra segunda hipótesis de trabajo.

\section{Poder disciplinario}

El sistema disciplinario surge a partir de mediados del siglo XVII en el ejército. Foucault dice:

La disciplina militar comienza a ser la confiscación general del cuerpo, del tiempo, de la vida; ya no es una sustracción de la actividad del individuo, es una ocupación del cuerpo, su vida y su tiempo (...). El poder disciplinario no es discontinuo, implica un procedimiento de control constante, uno está perpetuamente bajo la mirada de alguien, o en todo caso, en situación de ser observado (Foucault, 2005, p. 88).

Justamente esta es una de las formas de actuar sobre el individuo que poseen las Fuerzas Armadas. Pero estos sistemas están hechos para funcionar por sí solos, su responsable o director no es un individuo, sino una función ejercida por este, pero que también podría ser ejercida por otro. Incluso el responsable de un sistema disciplinario está contenido dentro de un sistema más grande, que a su vez lo vigila y en cuyo seno está disciplinado.

En el poder disciplinario, la función sujeto se ajusta a la singularidad somática ${ }^{14}$, la disciplina es la técnica de poder por la cual la función sujeto se superpone y ajusta a la singularidad somática. Es decir, el poder disciplinario fabrica cuerpos sujetos, es individualizante (p. 77).

Cuando analizamos planes y programas, llegamos a la conclusión de que el discurso de la doctrina se ajustó a la moralidad, y el discurso de la psicología a la tecnología. La psicología como disciplina habilitó durante la dictadura (no solo en dictadura) a la formación del individuo bajo el discurso de la tecnología.

No hay que confundir norma y disciplina. Las disciplinas apuntan a los cuerpos con una función de adiestramiento; la norma es una medida, una manera de producir la medida común. En una dimensión, el poder es llamado disciplinario, pero la disciplina es solo un aspecto de él. 
Allouch (2007, pp. 19-20) hace mención a que, dentro de las instituciones ${ }^{15}$ :

[...] Se conformó una especie de frente psi y se le devolvió consistencia al humanismo, que tan trascendente vuelve al sujeto, quien debía escapar de toda evaluación... El recurso a ese sujeto pretende ser un arma contra la desastrosa y poderosa tentativa actual de reabsorción del sujeto en individuo. El individuo, el indivis, es el sujeto estadístico, vale decir, disuelto dentro de la estadística (la estadística supone que el mismo individuo responde a la pregunta tres $y$ a la pregunta doce del formulario que hay que llenar, a cada una y a todas las preguntas; eliminen esa suposición, y ya no es posible ningún cálculo).

La función psi, un término usado por Foucault (2005) concretamente el 9 de enero de 1974, parte de la idea de que el psiquiatra es alguien que dirige, socialmente tiene a su cargo la dirección de la conciencia, lo que le importa a Foucault es la

15 En este caso, Allouch (2007, p. 19) está cuestionando la posición del psicoanálisis dentro de la episteme y, por otra parte, la manera en que el psicoanálisis tiene que presentarse en lo social a fin de poder subsistir, aunque fuera al modo de un parásito. manera como dirige. Al enfrentarse con el poder - coercitivo del delirio en el alienado, pero también para su entorno-, el psiquiatra se dedicará a dirigir al alienado, dándole a la realidad misma un poder coercitivo. Foucault lo llama tautología asilar: "Por lo tanto, darle poder a la realidad, y fundar el poder en la realidad, es la tautología asilar" (2005, p. 202). La voluntad del otro, del psiquiatra o del militar, equivale a la recuperación de una táctica de tratamiento moral.

Foucault se pregunta acerca de los alienados: ipor qué aparece la medicina?, si la disciplina impuesta en los asilos no se distingue de la que se ejerce en los cuarteles, las escuelas, los orfanatos, las cárceles.

Señala que no es el saber médico lo que constituye la diferencia entre el médico y un administrador cualquiera que detenta el poder, porque agrega que no hay conexión entre el saber y la práctica de los alienistas; ambos, el saber y la práctica, siguen su camino por su lado. En cambio, para conseguir que el alienado admita la realidad que se le contrapone y que se pretende que sea más coercitiva que su delirio, se apela nada menos que al cuerpo mismo del médico: un cuerpo importante, un cuerpo que se impone, un cuerpo como muestra Foucault, las dimensiones del mismo asilo (Allouch, 2007, p. 24).

Coincidencia casi exacta, con respecto a lo que sucede en la institución de formación docente, donde los actores institucionales, como administrativos, dirección, portero, se erigen funcionarios con poder institucional. 
En la institución de formación docente, no hay una única figura que detente el poder, muchas ocultan el poder, es decir, lo invisten, pero no es una marca visible.

La función $p s i$ "se encuentra en todas partes donde sea necesario hacer que funcione la realidad como poder" (2005, p. 225). La función psi prolifera en la institución educativa durante la dictadura, donde ingresa a través de las FF. AA., subestimando al estudiante y catalogándolo de subversivo.

Dice Foucault:

Y es a partir de esa forma mixta, entre la psiquiatría y la pedagogía, a partir de esa psiquiatrización del anormal, el débil, el deficiente etc., que se produjo, según creo, todo el sistema de diseminación que le permitió al psicólogo convertirse en esa especie de redoblamiento perpetuo de todo funcionamiento institucional (2005, p. 226).

Lo que sin duda preocupó a Foucault fue comprender cómo la acción de las normas en la vida de los hombres determina el tipo de sociedad a la que ellos pertenecen como sujetos.

Es preciso dejar de describir siempre los efectos del poder en términos negativos: excluye, reprime, rehúsa, abstrae, encubre, oculta, censura. En efecto, el poder produce, produce lo real, produce campos de objetos y rituales de verdad (Foucault, 1976, p. 75).

El poder produce, es, pues, una técnica que es posible llevar a cabo mediante la disciplina. La disciplina y la doctrina - entendida en este trabajo dentro de lo curricular - contribuyeron a normalizar a ese supuesto sujeto. En este sentido:

(...) Porque el discurso de las ciencias humanas tiene precisamente la función de hermanar, acoplar al individuo jurídico y al individuo disciplinado, hacer creer que el primero tiene por contenido concreto, real, natural, lo que la tecnología política recortó y constituyó como individuo disciplinado. Raspad al individuo jurídico, dicen las ciencias humanas (psicológica, sociológica) y encontraréis a cierto hombre; y de hecho, lo que presentan como hombre es el individuo disciplinado (...) individuo alienado, sojuzgado, un individuo que carece de autenticidad (2005, pp. 79-80).

Hay que ver la constitución del individuo a partir de determinada tecnología del poder; y me parece — dice— "que esta 
tecnología es la disciplina, propia del poder que nace y se desarrolla desde la edad clásica, que aísla y recorta, a partir del juego de los cuerpos, ese elemento históricamente nuevo que llamamos individuo" (p. 79).

Para las FF. AA., la creación de este individuo disciplinado fue acorde a su proyecto político-pedagógico. Desde lo curricular, la psicología lo habilitó; parafraseando a Foucault, tenemos el desarrollo de toda una tecnología disciplinaria que puso de manifiesto al individuo como realidad histórica, como elemento de las fuerzas productivas, como elemento también de las fuerzas políticas; y ese individuo es un cuerpo sujeto, atrapado en un sistema de vigilancia y sometido a procedimientos de normalización.

Las FF. AA. se encargaron de imponer una lógica de guerra, a través de destituciones arbitrarias y demás tácticas y estrategias que intentaron individualizar, es decir, que habilitaron la racionalización de la gestión del individuo.

\section{El orden en lo institucional}

Es interesante cómo desde lo curricular se da la orden al colectivo, el cual tiene relación directamente con individuos; este fenómeno panóptico es evidente en la institución formación docente. Es así como se evita la formación de colectivos de sujetos. Si bien tenemos bien identificados a los individuos, la figura del poder está completamente desindividualizada. Vigilar lo que sucede, vigilar si todo está en orden y vigilar si el director dirige como corresponde, vigilar al vigilante que vigila (2005, p. 100). Estamos frente a la formación por parte de las FF. AA. de un espacio político, con intención de proyecto pedagógico.

Pensamos que, para las FF. AA., la institución podría haberse convertido en un problema en cuanto a la consecución de su proyecto. Por lo cual implementó el sistema de control, de imposición del orden dentro y fuera de las instituciones de formación docente. Es decir, lo político como espacio público deja de ser un ámbito de libertades, porque dentro de lo público también lo privado estaba bajo control: conversaciones en pasillos, en sala de docentes e incluso dentro del aula. El espacio público se transforma en un símil panóptico donde la mirada ausente-presente se adueña de la intimidad. Creemos que este efecto trascendente se apoderó de nuestra cultura, porque invadió la vida privada dentro y fuera de las instituciones ${ }^{16}$. Dentro, se evidenció lo que llamamos orden de fachada institucional, donde las FF. AA. precisaron el orden que consideramos

\footnotetext{
16 Incluso en un trabajo sobre prensa realizado por una compañera de equipo, Aurora Saravia, se trabaja sobre cómo las imágenes son una fiel muestra de este discurso del orden público, donde se dice lo que las FF. AA. estaban haciendo por el bien de la sociedad, y esta lo acepta como normal, es decir, hay consenso en ello, o por lo menos parecería haber necesidad de consenso. Detrás de ello hay una máscara de miedo, donde esas imágenes tranquilizan. Este es el efecto del poder, dice Aurora "ya no hay adentro y afuera".
} 
una fachada ausente y oculta. Dado que la cara visible de la dirección de formación docente debía legitimar ese orden que se debía preservar, ahora bien, para preservarlo era necesario que existiera la posición contraria. Es necesario entonces pensar con detenimiento en ese orden de fachada; porque, por un lado, existe un orden presente, pero, por otro, hay una ausencia de quien vigila el orden, quien no es responsable visible por ese orden, pero cuyo fin era garantizarlo.

Ahora, ¿cómo lo hacían? Dentro de la institución, no se evidenciaba la presencia (física) de las Fuerzas Armadas ${ }^{17}$, pero había, montados dentro de ese panóptico, mecanismos de control que no necesariamente pasaban por la presencia de las FF. AA., tampoco por la dirección, figura presente, visible y con cierta jerarquía dentro de la entidad, sino que había otras presencias ausentes con el poder de decidir en forma total sobre la institución. Es desde aquí que se ejercen el poder y la necesidad de garantizar ese orden, a través de la vía de lo visible. Se trataba de garantizar la seguridad para evitar lo disruptivo, por ejemplo, docentes subversivos cesados en el cargo — se supone que fueron cesados por ser opositores al régimen - o la figura del estudiante etiquetado como subversivo, transgresor del orden. Dice Calveiro: "siempre el poder muestra y esconde, y se revela a sí mismo en el momento que lo exhibe como en lo que oculta" (1995, p. 25).

La estrategia de las FF. AA. fue pretender reencarnar el orden, ¿por qué reencarnar? Porque este orden ya estaba dado y no admitía discusión, lo paradójico es que defienden un orden, pero la excelencia del orden mismo es mediante la presencia de las FF. AA. ¿Cuál es la lógica de la representación de las FF. AA. en las instituciones, en este caso en formación docente? Digo representación, parafraseando a Luc Nancy, como aquello que presenta lo que está ausente de la presencia pura y simple. De alguna manera las FF. AA. son esa representación plena, son las que garantizaron la idea de ese orden ya dado, pleno.

Tal como plantea Myriam Southwel (2004, p. 121), el orden se convirtió en una idea organizadora para aquellos que participaron del régimen, el restablecimiento de un orden perdido fue la principal idea del discurso educativo. 


\section{Lo inclasificable:}

\section{el subversivo dentro de la institución}

Se inserta la figura del subversivo, aquel que niega el orden, la supuesta existencia de docentes y/o estudiantes opositores al régimen es la propia afirmación de la existencia del orden. Por ejemplo, si pensamos en los docentes: se los cesa del cargo, ¿solo por oponerse? ¿O porque esta es la forma de garantizar la existencia de un orden y eso brinda seguridad a nivel social? Es parte de la estrategia de los dispositivos disciplinarios, una de sus características es que son isotópicos, o al menos tienden a la isotopía, según Foucault, lo cual quiere decir varias cosas: que en un sistema disciplinario, el principio de distribución y clasificación de todos los elementos implica necesariamente un residuo; hay siempre, entonces, algo inclasificable. El punto contra el cual van a chocar los sistemas disciplinarios que clasifican, jerarquizan, vigilan, etc. será el elemento que no puede clasificarse, el que escapa a la vigilancia, el que no puede entrar en el sistema de distribución; en síntesis, el residuo, lo irreductible, lo inclasificable, lo inasimilable. Tal será el escollo en esta física del poder disciplinario. El desertor no existía antes de los ejércitos disciplinados, pues se lo concebía como un futuro soldado, el que dejaba el ejército para volver a él en caso de necesidad, cuando tuviera ganas o lo llevaran por la fuerza. Por el contario, desde el momento en que existe un ejército disciplinado, es decir, personas que entran en él, hacen carrera, siguen cierto escalafón y son vigilados de un extremo al otro, el desertor es quien escapa a ese sistema y es irreductible de él. El irreductible a la disciplina escolar solo puede existir con respecto a esa disciplina; quien no aprende a leer y escribir solo puede manifestarse como problema, como límite, a partir del momento en que la escuela sigue el sistema disciplinario (2005, p. 76).

Por qué y cómo se inserta en la institución formación docente la figura del subversivo, del residuo. Es necesaria, hay que sacarlos del sistema disciplinador porque contaminan al resto de los individuos y distorsionan el orden, por tanto, hay que eliminarlos. Dice Foucault (2005,p. 76):

(...) El poder disciplinador tiene la doble propiedad de ser anomizante, vale decir, de poner siempre distancia a una serie de individuos, exponer la anomia, lo irreductible, y de ser siempre normalizador, inventar siempre nuevos sistemas de recuperación, restablecer siempre la regla.

Evidentemente, con la presencia de un subversivo, las FF. AA. tenían en sus manos la materia prima para el castigo.

Foucault enumera las nociones que aparecen en las pericias, es decir, los objetos que la pericia pone 
de manifiesto, entre ellas: "inmadurez psicológica", "personalidad poco estructurada", "producción imaginaria", "juego perverso" (p. 29).

Es decir, lo que hay que castigar no es la explicación del porqué, sino la cosa misma. Es importante tener presente esta acotación para el momento histórico analizado, dentro de la institución era lo que sucedía: no se sabía con quién hablar, había que cuidarse de todos, hasta de los estudiantes, porque se venía un castigo, sin más explicaciones del caso, y la gente acataba el orden impuesto. De esta manera, se individualiza y, a la vez, se generaliza el miedo al castigo, en este caso podía ser la destitución o la cárcel.

Las FF. AA. pusieron lo que Foucault denominó blanco de castigo, el punto de aplicación de un mecanismo de poder, que es el castigo legal, de esta forma las FF. AA. legitimaron su poder.

Lo esencial de su papel es legitimar, en la forma del conocimiento científico, la extensión del poder de castigar a otra cosa que la infracción. Lo esencial es que permite reubicar la acción punitiva del poder judicial en el corpus general de técnicas meditadas de transformación de los individuos (Foucault, 2000, p. 31).

Así se constituyeron individuos, englobados en la categoría de la degeneración, que dio lugar a elaboraciones teóricas irrisorias, pero de efectos duramente reales (2000, p. 297). No nos queda duda alguna de que a partir de técnicas de disciplina, las FF. AA. pusieron en escena a un individuo a corregir. La aparición de un incorregible se produce entre los siglos XVII y XVIII en el ejército, las escuelas, los talleres y, un poco más adelante, en las familias mismas (p. 298).

Por tanto, las FF. AA. no inventaron nada, simplemente reprodujeron un sistema establecido y legitimado en las instituciones en otra época, reforzaron su presencia y ausencia a la vez. Es decir, al verse amenazadas, precisaron establecer el orden -lo hicieron de diversas maneras-. Lo consideramos una fachada ausente y oculta, porque dentro de la institución la cara visible era la dirección, que debía legitimar ese orden que era necesario preservar; ahora, para preservarlo es necesario que exista la posición contraria ${ }^{18}$. Por un lado, existe un orden presente, pero,

18 Esta posición existía antes, este punto puede analizarse, quizá partiendo de dos conceptos clave: laicidad y laicismo. Tema pendiente para próximos trabajos. 
por otro, hay una ausencia de quien vigila el orden, quien no es responsable visible por ese orden, pero cuyo fin era garantizarlo.

\section{A modo de conclusiones}

"El pensamiento (...) no debe buscarse, pues, solo en formulaciones teóricas como las de la filosofía

o la ciencia; puede y debe analizarse en cada forma de hablar, hacer y comportarse donde el individuo aparezca y actúe como sujeto de un aprendizaje, como sujeto ético o jurídico, como sujeto consciente de sí mismo y de otros". Michel Foucault (1984)

En el dispositivo se plasman las bases del pensamiento de las FF. AA., donde se explicita que la reestructuración de la educación debe instalarse para cambiar la realidad nacional. Soto (1975), en este sentido, argumenta:

En el quinquenio de 1968-1973, se inscribió sin lugar a duda, la historia más negra de la educación nacional (...) que no solo deformó sentimientos, sino que también sumergió en la ignorancia del conocimiento a seres útiles en nuestra sociedad, pues estos fueron los fines y propósitos de la subversión marxista encarnada desde la universidad hasta la escuelita rural más moderna. Debiendo entenderse que educación significa proporcionar orientación formativa integral, esto es, fortalecer el espíritu de la persona humana, enriquecer su mente $y$ robustecer su cuerpo.

La reestructuración ha logrado un orden de fachada, una vuelta a la calma para que funcionen los centros docentes, por ello entendemos que las materias del tronco común de formación docente no fueron realmente un recurso pedagógico, sino un mecanismo de control que instala el orden de fachada. Las FF. AA. garantizaban - bajo el orden de fachada - el control para supeditar sujetos a la autoridad; estrategia usada desde regímenes democráticos, donde el consenso determina la eliminación o negación de disensos; lo visible para la institución educativa debe ser el orden y su control.

La función del educador legitima esta idea clave para la instrumentación del proyecto político-educativo de las FF. AA. Es la figura estratégica para reproducir y repercutir ideológicamente en las futuras generaciones.

Romano $\left(2008^{19}\right)$ dice: "fue en la dictadura el momento en que más se ajustó un modelo de hombre y proyecto de sociedad, donde la

19 Extraído durante reuniones de trabajo sobre la línea de investigación Educación y Dictadura. 
educación estaba al servicio de un proyecto político". Un modelo de hombre centrado en la formación de la persona y un proyecto de sociedad donde lo central, según Soto, era cambiar la mentalidad de las nuevas generaciones, "a fin de que el niño y el joven de hoy sean el ciudadano del Uruguay que construirán la revolución que está en marcha" (Soto, 1975, p. 28).

En este sentido, podemos preguntarnos qué tradiciones pedagógicas enfrentó lo que podríamos llamar pedagogía autoritaria de la dictadura, o mediante qué problemas anteriores no resueltos la dictadura logró legitimarse en alguna medida. Del mismo modo, una indagación en estos temas fácilmente lleva a la pregunta por las posibles influencias que ejerza o haya ejercido esta pedagogía y estas formas de entender lo curricular en posdictadura.

Intentamos vincular lo curricular, expresado en planes y programas dentro de la institución, y esta última como ámbito estratégico donde desplegar el proyecto político pedagógico de las FF. AA.

Las instituciones no se reducen a lo simbólico, pero no pueden existir más que en lo simbólico, son imposibles fuera de un orden simbólico en segundo grado y constituyen cada una su red simbólica (Castoriadis, 1983, p. 201).

En esta red simbólica, intentamos articular el currículo con el instituto de formación docente concretamente ${ }^{20}$. Al contextualizar el proyecto de las FF. AA. fue inevitable deslindar al individuo foucaultiano, diríamos al funcionario institucional, dado que es quien lleva la marca de un saber supuesto.

Pensamos que hay un individuo visible en la institución formación docente, y hay sujetos que, a los efectos de nuestro trabajo, han desaparecido como resultado del proceso institucional. El docente fue un funcionario al servicio educativo, un individuo disciplinado, aquel que se encuentra en la cultura de la individualidad, y la yoicidad, que ha perdido el yo lingüístico. No tiene voz, porque es de otros, es la voz de la institución, por ende ha perdido su identidad, ha cedido su cuerpo.

La institución modeló a los sujetos a través del currículo, cuya función fue la reorganización del sistema educativo como estrategia política eficaz. Los sujetos fueron supeditados a normas internas, a reglamentos que actuaron sobre sus cuerpos para moldearlos a su manera, lo cual es coherente con

20 Este trabajo nos habilitará al estudio de la conformación del ser docente en dictadura y sus resistencias. Será analizado a partir de entrevistas a docentes que trabajaron en dicha institución durante el régimen. 
los fines educativos de las FF. AA. Es decir, fue un logro disciplinador para ellos, porque, como se mencionó anteriormente, este proyecto no solo fue educativo, sino cultural. Por lo que estamos diciendo, logaron individualizar a la gran mayoría de nuestra sociedad. No estamos aludiendo a la responsabilidad de un actor en especial, sino que fuimos y somos responsables de que, en general, la tecnología del poder haga y deshaga con nuestros cuerpos, en función de intereses políticos, sociales, económicos. Foucault dice: "y ese individuo es un cuerpo sujeto, atrapado en un sistema de vigilancia y sometido a procedimiento de normalización" (2005, p. 79).

Es interesante pensar, como dice Foucault, en que:

Tradicionalmente el poder es lo que se ve, lo que se muestra, lo que se manifiesta (...) Aquellos sobre quienes se ejerce el poder pueden permanecer en la sombra; solo reciben la luz que les es concedida de esta parte del poder (...) Con la disciplina según la lógica de la norma, la sombra llega a la luz. En la disciplina, son los sujetos quienes han de ser vistos. Esta iluminación asegura el dominio del poder que se ejerce sobre ellos (Foucault, 1976, p. 65).
Incluso, dentro de lo que Foucault Ilama protopsiquiatría, se trata del poder (del delirante) contra el poder (del analista), identificado como super-poder o como intensificación de la realidad. Nosotros podemos agregar la realidad del inconsciente, aunque no cambie, pero sería interesante su análisis. Veamos al respecto las palabras de Rifflet-Lemaire:

El inconsciente para Lacan es un discurso pronunciado en persona, en primera sobre todo. Es probable que haya sufrido modificaciones debidas a la represión, otras las sufre con ocasión del retorno a la conciencia por la labor de la censura. El inconsciente se halla integrado en la totalidad de la persona y contiene actos y pensamientos del Yo en su historia (1981, p. 218).

Hay conexión entre lo inconsciente y la ideología del régimen, dado que el inconsciente es un fragmento de discurso que permitirá restablecer una continuidad coherente en el discurso consciente.

El inconsciente, a partir de Freud, es una cadena de significantes que en alguna parte (en escena, escribe) se repite e insiste por interferir en los cortes que le brinda el 
discurso efectivo y la cognición que él informa (Lacan, 1960, p. 779).

El inconsciente es una letra, un sistema letrado, que viene a interactuar en el discurso consciente, a propulsarse en las lagunas del texto manifiesto. Estas lagunas se localizan en lo que Lacan ha denominado las formaciones del inconsciente (lapsus, chistes, actos fallidos, etc.).

Lacan (1952), al respecto, dice: "el inconsciente es ese capítulo de mi historia que está señalado por un blanco u ocupado por una mentira: es el capítulo censurado".

Brillante, y pocas veces tan clarificadora esta cita de Lacan, la verdad puede volver a encontrarse, puede estar inscripta en otra parte, en el cuerpo donde el síntoma histérico se descifra como inscripción y muestra la estructura de un lenguaje, en las tradiciones y leyendas, en los documentos y archivos: recuerdos de mi infancia.

Por lo antes mencionado, la ideología del régimen militar continuó latiendo en la institución y dejó sus huellas, al igual que el inconsciente, debido a que es parte de la relación imaginaria de los sujetos con sus relaciones sociales.

Puede ser un tema de próximos trabajos rastrear desde la universidad estas huellas desde planes y programas, desde disciplinas que remiten a la educación, como la pedagogía. Por cuanto lo pedagógico remite a lo deóntico, es decir, a aquello que se plantea como necesario, lo que debe hacerse, implica lo obligatorio y lo normativo, es un instrumento que podemos denominar parafraseando a Foucault: tecnológico de poder. Sería interesante vincular la pedagogía con la psicología, dado que a principios del siglo XIX la pedagogía se vio casi sustituida por la psicología y la sociología. Podríamos entenderla como una técnica o instrumento de control consciente de poder social, al igual que la psicología.

\section{Referencias bibliográficas}

Abbagnano, N. y Visalberghi, A. (1987). Historia de la pedagogía. México: Fondo de Cultura Económica.

Allouch, J. (2007). El psicoanálisis ¿es un ejercicio espiritual? Respuesta a Foucault. Buenos Aires: Literales.

Apprato, C. y Artagaveytia, L. (2004). La educación en el Uruguay de la dictadura (1973-1985): la era militar. Montevideo: Banda Oriental. 
Behares, L. (2004). Didáctica mínima. Los acontecimientos del saber. Montevideo: Psicolibros.

Bottaro, J. (1998). El autoritarismo en la enseñanza. Montevideo: Clip.

Caetano, G. y Rilla, J. (1987). Breve historia de la dictadura. Montevideo: Banda Oriental.

Calveiro, P. (1995). Poder y desaparición. Los campos de concentración en Argentina. Buenos Aires: Coplihue S.R.L.

Campodónico, S.; Massera, E. y Sala, N. (1991). Ideología y educación durante la dictadura. Montevideo: Banda Oriental.

Castoriadis, C. (1983). La institución imaginaria de la sociedad. Barcelona: Tusquets.

Castro, E. (2004). El vocabulario Michel Foucault. Argentina: Prometeo.

Coll, C. (1989). Conocimiento psicológico y práctica educativa. Barcelona: Barcanova S. A.

CONAE (s/d) (1977) Planes y Programas para la Formación Docente, Ordenanza No 29. Programa de Magisterio, año 1974.

Fernández, L. (2005). Instituciones educativas. Buenos Aires: Paidós.

Foucault, M. (1976). Historia de la sexualidad. La voluntad de saber. México: Siglo XXI. (1992): Genealogía del racismo. Madrid: La Piqueta. (2000). Los anormales. Buenos Aires: Fondo de Cultura Económica.

(2005): El poder psiquiátrico. Buenos Aires: Fondo de Cultura Económica.
( 1984): Histoire de la

sexualité, 2. L'usage des plaisirs. París: Gallimart

Frigerio, G. (comp.) (1991). Currículo presente. Ciencia ausente. Normas, teorías y críticas. Buenos Aires: Miño y Dávila Editores.

Kaufman, C. y Doval, D. (1997). Una pedagogía de la renuncia. El perennialismo en Argentina (19761983). Rosario: Editorial Lux.

Lacan, Jacques, Subversión del sujeto y dialéctica del deseo en el inconsciente freudiano. En Lacan. Escritos 1. Siglo XXI, p: 773-808. Buenos Aire (Comunicación a un Congreso reunido en Royaumont, 19 al 23 setiembre de 1960).

LACAN, Jacques, (1952) Función y campo de la palabra y del lenguaje en psicoanálisis. En Lacan. Escritos 1. Siglo XXI, Buenos Aires 227-310. (Informe del Congreso de Roma celebrado en el Instituto de Psicología de la Universidad de Roma, 26 y 27 de setiembre de 1953).

Lourau, R. (2007). El análisis institucional. Buenos Aires: Amorrortu.

Rajchman, J. (2001). Lacan, Foucault y la cuestión de la ética. México: Epeele.

Rifflet-Lemaire, A. (1981). Lacan. México: Hermes.

Ruiz, E. (1998). Escuela y dictadura, 1933-1938. Montevideo: Udelar-FHCE.

Programa General de Formación Docente, s/d (1965) Consejo Nacional de Educación Secundaria. 
Programa de Magisterio, (s/d) (1955) Consejo Nacional de Educación Primaria.

Sarlo, B. (2005). Tiempo pasado. Cultura de la memoria y giro subjetivo. Buenos Aires: Siglo XXI.

Smola, J. (2006). Reflexiones sobre la dimensión política del lenguaje. En: J. Martín y G. Suazo (comps.), La política las palabras y la plaza. Buenos Aires: Del Estante.

SOTO, J.R. (s/d) (1975) Proceso de la Educación en el Uruguay. Conferencia. CONAE.

SOUTHWLL, Myriam (2004) Ciencia y penitencia: dictadura, pedagogías restrictivas. Capítulo V. Tomo II. 